\title{
The European Union and the Energy Transition
}

\author{
Marc-Antoine Eyl-Mazzega and Carole Mathieu
}

\section{Introduction}

The low-carbon energy transition in the world is today taking place unevenly and too slowly to preserve the climate and biodiversity. $\mathrm{CO}_{2}$ emissions have been rising (2016, 2017, and 2018) albeit they should peak rapidly according to Intergovernmental Panel on Climate Change (IPCC) reports. 2019 and 2020 could see a first slow down though due to the global economic situation and greater deployment of renewables and use of gas in replacement of coal power. But way not enough to follow pace with an $8 \%$ yearly decline needed toward 2030 for a significant chance to limit global warming to $1.5^{\circ} \mathrm{C}$. The world is experiencing unprecedented heat waves, forest fires, accelerated glacier melt, draughts, and extreme weather events, resulting from climate change and potentially contributing to harmful feedback loops. And governments' commitments are insufficient: in the long term, with the current policies in place, the world is on a $+3{ }^{\circ} \mathrm{C}$ trajectory (IPCC 2018). While our house is burning, President Trump has introduced a process of withdrawing from the December 2015 Paris agreement ${ }^{1}$ and has been diluting multilateral efforts such as in the G7 or G20. Brazil is returning to a policy of deforestation, and Australia is putting short-term economic gains before climate action. Massive fires covering two times the size of Belgium have not yet prompted a policy change. At this stage, only a global recession could curb emissions, provided that recovery measures are then aligned with the Paris Agreement. Most countries in the world have not yet kickstarted a low-carbon transition process and in the best cases, renewable deployment

\footnotetext{
${ }^{1}$ This withdrawal, effective in November 2020, should not hide three realities: the boom in deploying renewable energy sources in the US is going ahead, albeit more slowly, and the US intends to vie with China for the leadership in the innovation of low-carbon technologies. Moreover, US civil society, certain states like California, cities and companies remain mobilized and influential.
}

M.-A. Eyl-Mazzega $(\bowtie) \cdot$ C. Mathieu

Institut Français des Relations Internationales (IFRI), Paris, France

e-mail: eylmazzega@ifri.org 
just avoids building additional coal-fired power generation capacity. Electricity supply security and economic development are legitimate priorities of many emerging economies, ranking higher than the reduction of greenhouse gas emissions. At best, their concern is about reducing air pollution in cities, which often but not always comes with co-benefits in terms of climate change.

Despite the sense of urgency, the inertia of energy systems is strong and coal and oil are going to continue dominating the global energy mix for a long time. With rising demand for electricity, a fundamental challenge is to decarbonize the power sectors globally, while also spending important efforts on the heating and cooling, industry and transport sectors, and on other greenhouse gases than $\mathrm{CO}_{2}$, such as methane. The world needs a minima to double investments into renewable energy sources and energy efficiency, as well as the deployment of a mix of solutions including energy efficiency, reforestation, Carbon Capture, Utilization and Storage (CCUS) technologies, decarbonized hydrogen, biofuels, biomass, electric vehicles, LNG in the maritime and road freight segments, and nuclear. Last but not least, efforts to fund adaptation measures still need to be strengthened considerably.

Since the Lisbon Treaty, the EU has stepped up its environmental policies and has been able to expand and increasingly integrate both energy and climate policies. This process has seen the introduction and reinforcement of longer term decarbonization objectives, and a growing role of the climate dimension in EU's internal and external energy policies. The EU set for itself sustainable energy targets for 2020, which will be achieved (with some concerns though remaining over energy efficiency) and actively participated in the December 2015 Paris Agreement process.

Responsible for $10 \%$ of global yearly emissions, the EU has become a global leader in the energy transition. Decarbonization targets for 2030 have been reinforced in 2018 and a debate over longer term (2050) decarbonization options and pathways has been opened in 2019, with a growing consensus on the need to target climate neutrality by 2050 . EU's energy policy is now a decarbonization policy with several pillars: decarbonization and competitive, secure, and integrated energy markets. Yet this is a long and complex process and the long journey toward full decarbonization has just been started, while climate and biodiversity preservation call for unprecedented, massive, and urgent action. Despite having remarkable policies and ambitions, the EU is also confronted with inconsistencies and shortcomings. Matching ambition with actions will be the most challenging.

Following the 23-26 May 2019 European elections and the new five-year mandate for the European Parliament and the European Commission starting on November 01, 2019, and against the backdrop of rapid degradation of the global climate and biodiversity situations, the EU energy and climate policies are at a turning point and on the threshold of unprecedented developments. Ursula van der Leyen, President of the European Commission, referred to environmental protection as the "greatest responsibility and opportunity of our times" and committed to proposing a Green Deal in the first 100 days of her mandate. Over the summer of 2019, a swift, broad, and radical reaction has gained political support and a majority of Europeans see climate action as a priority. The next challenge is to clarify decarbonization pathways, define the key priorities, and adopt the right instruments and policies. In terms of industrial 
and economic cycles, 2050 is practically tomorrow. Lastly, citizens are often not willing to bear a high financial burden for the transition. Cost-efficiency, and fair redistribution of costs and dividends among citizens, Member countries, economic sectors, and territories, will be essential.

This chapter looks at some of the strategic energy and climate policy issues for the next five years, elaborates on how the EU energy and climate policies may be shaped, and what are the global implications.

\section{The Status of the European Energy Transition}

The EU is almost on track to meet its 2020 climate and energy package targets (the 20-20-20 objectives), ${ }^{2}$ a policy that had been enacted in 2009. In 2018, renewables accounted for over $32 \%$ of total electricity generation and $\mathrm{CO}_{2}$ emissions from the power sector saw a slight decrease from 2017 and an overall significant fall from 1990 levels. In most countries, renewable investments are strong, notably in solar power, with falling deployment costs, especially for offshore wind.

The EU has developed a number of useful tools to support the energy transition: the European Investment Bank, the Emission Trading System (ETS) which has been reformed, pushing up carbon prices over $20 \mathrm{EUR} /$ tons for the first time in a lasting manner since summer 2018, and several infrastructure investment funds, as well as innovation funds and programs, such as Horizon 2020, becoming Horizon Europe under the next long-term EU budget.

Most EU governments have introduced plans to phase out coal from power generation, with $70 \mathrm{GW}$ out of $140 \mathrm{GW}$ of installed capacity expected to be phased out by 2030 . Germany's coal generation (37\%) will be progressively phased out by 2038 at the latest while Poland's high dependence ( $80 \%$ of power generation) will require special considerations and incentives to support structural change.

Further steps in this energy transition process included the objective to establish a European Energy Union developed by the European Commission to foster the integration of energy markets and convergence of policies. The Clean Energy Package for All Europeans, negotiated and finalized over the period 2016-2018, is a fundamental, highly complex tool that has introduced improvements in the functioning of the internal energy market, encouraged innovation and enabled a more active role for energy consumers. The EU is betting on the complementarity of its national energy mixes and the internal energy market to meet the rising flexibility needs as intermittent renewables are deployed. Institutional changes have also happened with the creation of a Vice President for the Energy Union and the adoption of a Regulation on governance, requiring Member States to adopt consistent planning tools and engage in cross-border consultations, while also giving the EU Commission the

\footnotetext{
${ }^{2} 20 \%$ increase in energy efficiency, $20 \%$ reduction of $\mathrm{CO}_{2}$ emissions from 1990, and $20 \%$ renewables in final consumption by 2020 .
} 
Fig. 1 GHG emissions in the EU by sector, in 2017. Source European Environmental Agency

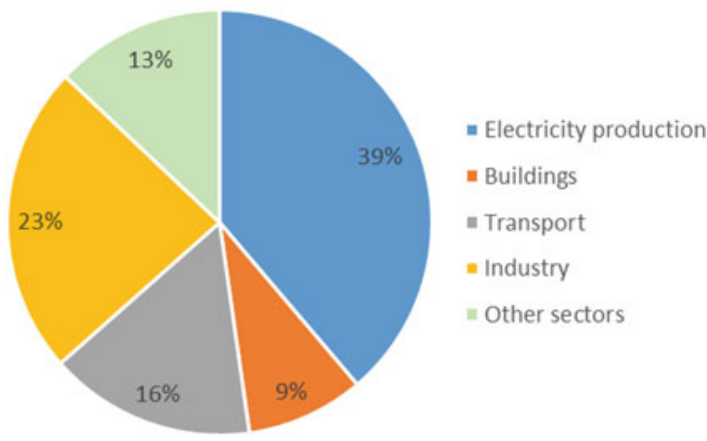

right to review and issue recommendations on the draft plans. The challenge is now to ensure a proper implementation of the package.

With the completion of the 2016 Clean Energy Package, the EU has confirmed the permanence of its climate commitments and its increasing role in policies implemented nationally. This is reflected in the commitment of raising the share of renewables to $32 \%$ of final energy consumption (from an initial target of $27 \%$ ) and improving energy efficiency by at least $32.5 \%$ by 2030 (up from $27 \%$ compared with 2005). Decisively also, in raising the objective to reduce $\mathrm{CO}_{2}$ emissions from 30 to $40 \%$ by 2030 compared with 1990. Lastly, the package took steps to improve electricity market integration and security (capacity reserves, cross-border flows) and to accelerate the decarbonization of the transport sector (Fig. 1).

These positive results nevertheless hide strong discrepancies among Member countries and important challenges. These include, notably:

- Costs of renewable support schemes grow, not least due to the increasing grid costs; bottlenecks in high transmission lines are not removed, such as in Germany, where four north south lines are planned but will face huge delays; social resistance to renewables and transmission lines is growing, with over 40,000 wind miles installed in Germany and 8000 in France; Overall system costs will further increase with the need to deploy electricity storage technologies, or demand-side management systems. There is a strong case for incentivizing larger renewable projects in suitable locations, where grid connection costs can be minimized. Yet acceptability issues can be an obstacle to cost-effective deployment of renewable energy sources, as recent experience shows in France. It remains to be seen whether reaching $65 \%$ of final electricity consumption as is planned in Germany with mainly wind and solar will be possible - that would require at least doubling the number of installed windmills considering that the best spots are often already taken, that interconnection challenges arise, grid costs increase and that social acceptance for mills and grids is increasingly a challenge. Last but not least, the land costs for solar could increase - the declining deployment trends in H1 2019 for renewable energy sources in Germany and France require a careful watch in this context. 
- Lignite in most cases is more competitive than natural gas for power generation so that in Germany, for example, the increasing deployment of renewable energy sources has kept coal generation at almost steady level in past years while gasfired power generation took a hit. The situation is now improving with the fall in gas prices and higher costs for $\mathrm{CO}_{2}$ allowances, enabling a market-driven switch between low-efficient coal plants and high-efficient gas plants. France has made nuclear power a pillar of its mix and benefits from the legacy of its very low emitting power generation fleet. It has been proposing to complete the EU ETS with a regional floor price for $\mathrm{CO}_{2}$ in the electricity sector, in order to accelerate and facilitate the phasing out of coal, which Germany has refused so far in order not to give advantages to France, an important industrial competitor and electricity exporter (Matthes 2017). This position could change though as a further reform of the ETS is planned. In line with the 2018 coalition agreement, Germany aims at producing more than $65 \%$ of its electricity from renewable energy sources by 2030 (35.2\% of output in 2018).

- The EU has no competence in tax policy, nor on the energy mix of national countries, nor on social policy. A question is whether to enlarge the ETS to other sectors currently not covered (aviation, buildings, maritime transport...) or whether to proceed with separate taxation of these sectors. Moreover, the ETS could be fully replaced by a tax system at EU level, which would be politically challenging but worth discussing. The ETS only covers about $45 \%$ of total $\mathrm{EU} \mathrm{CO}_{2}$ emissions. Its latest reform was driven by the creation of a capacity reserve mechanism and was an important step forward as prices soar to over $25 \mathrm{EUR} /$ tonne, yet further reforms will be needed to reflect the withdrawal of the United Kingdom following Brexit, but also the closure of coal-fired power plants, the increasing deployment of renewables and higher energy efficiency targets. The carbon market could still concentrate on accelerating low-carbon investments in heavy industries, but the price incentives are limited in this case because of the free allocation of quotas and measures taken nationally to compensate the indirect cost of $\mathrm{CO}_{2}$ for energyintensive consumers. These developments once again challenge the relevance of carbon pricing tools in Europe. Examination of the question is today compartmentalized, as unanimous voting by Member States prevails in tax matters. The next ETS reform is expected in 2021.

- Efforts in energy efficiency have slowed down and while low hanging fruits have been tapped, the challenge will be to further deepen efforts in the residential sector and transport sectors. After a gradual decrease over 2007-2014, primary and final energy consumption have increased again over the recent years, in part because of higher economic activity and relatively low fossil fuel prices, but also because of soaring sales of large cars and a slow down in energy efficiency improvements in the building sector. The trend will have to reverse shortly if the EU wants to fulfill its 2020 commitments.

- The decarbonization has so far largely focused on the power sector, with mixed results, but not yet on the transport and industry sectors. The Clean mobility 
package adopted in early 2019 is an important milestone in accelerating the decarbonization of the transport sector. The new 2030 targets will accelerate electrification but not remove the thermal engine. They will be hard to achieve and drew very strong resistance from the automotive industry as they were negotiated. Fundamental decisions must also be made as to whether the mobility will be all-electric or whether one should give a greater role to hydrogen, green gases, or LNG/CNG, especially for freight transport. If biofuels, alongside hydrogen, are the only realistic ways in future to decarbonize partly the aviation sector, then a lot of innovation funding should also go in this direction.

- Most of the focus has been on $\mathrm{CO}_{2}$, but not so much on other polluting gases such as methane-at a time when President Trump is taking steps to ease regulation on US methane emissions and when gas flaring is increasing globally, notably in the US.

- There are important discrepancies among member states' priorities and the recent submission of national climate plans shows that progress toward the common targets is uneven and that more than a last mile is missing to reach the set objectives. The gaps between aggregated contributions and the EU targets could be as big as $1.6 \%$ points for renewables, and as big as $6.2 \%$ points for primary energy consumption (European Commission 2019a, b, c).

- Set aside long-term contracts with guaranteed prices for renewables projects, there are no price incentives for long-term investments into low-carbon electricity generation capacity, due to the increased volatility on wholesale markets and the expected decline in prices as more renewables with zero marginal production costs are connected, especially during day time. This fundamental market failure is not addressed and will become a growing issue given that the current generation overcapacities will progressively be reduced and that massive investments will be needed to offset the ageing thermal fleet (coal, gas, and nuclear) and expand lowcarbon assets. With more renewables, wholesale prices will become increasingly volatile and could well decrease instead of increasing as could be the case in the medium term while carbon prices grow and large thermal capacities are still in the mix. The shift to decentralized production and self-consumption is also triggering new challenges in terms of regulation and distribution of network costs between the different categories of power consumers. To avoid a potential "death spiral" and excessive cross-subsidies, the structure of unitary grid fees may need to be adjusted.

- There are strong divergences as to how far electrification of uses can or should go: while it will have to increase in the transport or residential sectors, the gas industry, for example, claims it needs to continue playing a key role in pointing to the unique value of the gas and storage infrastructure as energy systems will need greater flexibility, especially for the winter, and as the transition needs to happen at the lowest costs possible, which the existing, sunk cost gas infrastructure can facilitate. Yet decarbonizing natural gas is expensive and can only be realized in a system approach. Producing biomethane, for example, costs almost eight times more than natural gas (at 01/2020 prices), but the simple cost comparison with other fuels has limits: when externalities from biomethane production are included (in 
terms of $\mathrm{CO}_{2}$ footprint, territorial development, energy security, agro-ecological transition, replacement of fossil fuels in the transport sector) biomethane has clear advantages.. What matters is to properly understand and assess what are the future impacts on electricity demand flexibility, on managing peak loads, and hence on short and longer term storage, what are technological options for electricity storage and their costs, and also to have a clear vision in terms of sequences of the energy transition: natural gas will play a key role for the next decade in providing system flexibility, especially if it is cheap and competitive (which is the case in mid-2019 but could change again), before progressively having to disappear (unless one produces decarbonized hydrogen from gas with CCUS). If climate neutrality is the ultimate objective, remaining emissions that are to be compensated through carbon sinks will not come from natural gas, but from the agricultural or aviation sectors, or specific industries. And the switch to "green gases" is important but will not impede a progressive yet necessarily important reduction in the role of natural gas per se, that could nonetheless boom elsewhere in the world if it is competitive so that global gas players will be able to adapt their strategies. Decarbonized hydrogen will have to play a key role in the refinery sector first and then to decarbonize the industrial sector and probably also, parts of the maritime and freight transport segments. It remains to be seen whether decarbonized hydrogen will play a role in the passenger car segment, residential heating, or electricity storage to meet seasonal fluctuations.

\section{The New Political Context from 2019: Pressure for Accelerating and Deepening the Energy Transition}

In 2018, discussions have opened on objectives and strategies for 2050, with the exploration of trajectories going as far as carbon neutrality by 2050 in an unprecedented joint undertaking involving many Directorates from the Commission (European Commission 2018). Different trajectories and energy mix options were laid out for different decarbonization objectives in this major exploratory analytical document that aims at informing discussions on the options available.

Systematic transformations in governance and public policies, company strategies, and citizens' behavior are required. These transformations need to be grounded in the broadest consensus possible. Indeed, European policies so far were established in a context and with objectives that do not correspond to deep decarbonization and were largely focusing on market integration, competition, and supply security in order to serve the consumers' interests. The challenge now is to adapt them to this profound transformation.

After the European election that saw climate issues dominate concerns of citizens in many Member States, and in the face of the growing climate urgency, the discussion over the 2050 targets has clearly shifted: while carbon neutrality was opposed notably 
by Germany, all but one EU member states now decisively support that objective as highlighted at the December 2019 European Council.

The presentation of the European Green Deal on December 03, 2019 marked a tipping point. The Green Deal is targeting all pollutions and environmental degradations. It is a sustainable economic growth strategy which aims at fostering the well-being of Europeans. It aims at decarbonizing all economic sectors, cutting all greenhouse gas emissions, mobilizing more funds and budgets, aligning all Member countries and policies as well as using all available solutions and low-carbon technologies. The Green Deal announcement showcased the new European raison d'être ensemble. And a clear commitment to avoid social and territorial inequalities - a Just Transition Fund has been created to help vulnerable regions. This means closing the chapter of marginal improvements and considering profound socioeconomic changes.

At the same time, the EU has agreed on a taxonomy of sustainable investments, setting a global benchmark that will empower finance to foster the energy transition. A number of action plans are to be rolled out across 2020. A Climate Law is to be enacted, precising the objective and the policy framework. Objectives for 2030 are to be revised. An industrial strategy for low-carbon technologies is to be released, focusing notably on batteries and clean hydrogen. The aims should be to secure critical metals, design norms, protect industries, support the scale-up of innovation, create ecosystems and clusters along the value chain, impose carbon low-carbon footprints in tenders and materials (eco-design directive), and foster recycling operations. A new budget for 2021-2027 with higher spending toward climate change mitigation is to be agreed upon. An external strategy will follow. This Hercules task will not be an easy journey and there are already controversies, obstacles, and resistances. But the EU has shown that as one of the world's largest historical emitters, it is taking its responsibilities in bearing higher costs and is aiming for global leadership. If successful, this could reinforce EU's influence globally.

The key challenge now is to deliver as the easy low hanging fruits are no more available. There is no magic solution. The European Green Deal will require new financing (a 1 Trillion package until 2030 has been identified, which is likely to be insufficient though) but also the better use of existing tools and their refocusing on climate concerns. Targeting climate neutrality by 2050 requires choosing the most cost-competitive options and trajectories, fostering regional coordination of policies and investments, avoiding stranded assets, picking the right technologies, and giving them the large deployment scale and perspective needed to reduce costs. It requires giving the industry the rights tools, incentives, and protection to conduct this transformation while remaining competitive. While technological neutrality is a condition for political consensus and efficiency, a holistic approach focusing on the entire system costs is needed, rather than an individual focus on specific technologies or sectors that masks the system-wide implications.

Another policy challenge is to accommodate the new role played by cities and regions, in order to facilitate structural change and strengthen regional cohesion. And last but not least, to ensure social cohesion and a fair distribution of costs and benefits from this transition that will have to rely on a large consensus and joint 
action from the industry, the citizens and the government. The costs of reaching carbon neutrality will be very high, yet much lower than refusing to take action and facing the most adverse impacts of climate change. The social acceptability of this transformation will depend on two main factors: the ability to provide assistance to those who will be the hardest and most directly affected by the changes, such as low-income households and works in the carbon-intensive sectors; and the ability to make the energy transition a lever for creating quality jobs and added value on the EU territory. Without a robust and steady support from the population, efforts in decarbonizing the economy are at risk of being delayed, diluted or called in question at each election round, which would make the whole process ineffective and costlier.

There is no denying that carbon pricing will need to cover all sectors and increase in a progressive and predictable manner. Acting in a facilitating role, the EU should revise the 2003 Directive on energy taxation to not only ensure that inefficient fossil fuel subsidies are removed and that environmental considerations are included in all national schemes, but also require that fiscal equity is given due attention.

The EU will have to review its state aid policies and the market liberalization and competition dogmas from the 1990s and 2000s as the deep decarbonization of the power system cannot happen in the current market environment. More state intervention is needed to guarantee long-term prices, reduce risks, and borrowing costs. This will have to include nuclear power, which is controversial given the opposition from Austria, for example, but one thing is clear: there will be no effective and deep decarbonization by 2050 without new nuclear power constructions in the EU that at least compensate for the closure of ageing plants, even extended. But new investments in nuclear will be impossible without guarantee schemes like the ones implemented in the United Kingdom (UK) for Hinkley Point C. These triggered an investment decision by state-owned utility EDF, but proved to be insufficient for private actors like Hitachi. Against this backdrop, it is worth paying attention to UK's envisaged introduction of a "Regulated Asset Base" (RAB) model for new nuclear project, as being planned by the Secretary of State for Business, Energy and Industrial Strategy. Its goal is to reduce the cost of raising private finance for new nuclear projects, thereby reducing consumer bills and maximizing value for money for consumers and taxpayers. In the coming months, a discussion will have to start on a new electricity market design to facilitate the large investments needed.

On a similar note, a political agreement is needed to bring down the climate wall between western and eastern European countries. This agreement should include on one side strong commitments for a rapid coal phase-out, and on the other side the mobilization of the dedicated Just Transition Fund complementing existing instruments (Cohesion policy, Modernization and Innovation funds, Invest EU, etc.), and focused efforts by the European Investment Bank to support integrated territorial development strategies in carbon-intensive regions. 


\section{Strategic Economic Challenges Ahead}

\section{a. The industrial dimension of the energy transition}

The energy transition process bears new industrial risks and threats related to the control of value chains of low-carbon technologies and the operation of systems:

- technologies, innovations/intellectual property and low-carbon technology value chains (autonomous mobility, nuclear power, decentralized production, renewable energies $)^{3}$;

- access to markets and tenders (in public transport, nuclear energy, wind and solar power, hydroelectricity infrastructures, sustainable cities).

- assets (investments and shareholdings in companies operating in electricity, gas, digital technologies, data-processing and data);

- standards (electricity, batteries, electric mobility, interconnectors, networks, data protection);

- cyber-security;

- information and image.

The EU will have to take further actions and steps to address these challenges which it has started to recognize. The EU regulatory framework needs to foster both demand and competitive supply of low-carbon solutions. That will require to further confront policies and actions from emerging and established powers such as China (and its Made in China 2025 strategy) or the USA.

China has defined a Made in China 2025 strategy which includes an empowerment dimension and the mastery of energy technologies. The country has already taken, or is seeking to take, dominant positions in the whole value chain of the main technologies involved in the low-carbon energy transition. This is the result of a proactive strategy which combines internal support for innovation (one-third of patents in low-carbon technologies are Chinese) (IRENA 2019), an industrial policy (large state groups receive financing, demand-side support, a capacity to take risks and cooperate throughout the value chain), and technological looting or the transfer of technology as a condition for Foreign Direct Investment. China moreover benefits from its huge domestic market which provides economies of scale while competition between state groups is weak. The country also benefits from the errors and mistakes of its competitors, notably the EU and most of its Member States. They have left aside some of these issues and even directly contributed to China's dominance by transferring polluting industries to China, and by accepting forced technology transfers. Moreover, for a long time they only protested weakly against very unequal Chinese

\footnotetext{
${ }^{3}$ Strategic technologies in the energy transition include nuclear power; onshore and offshore wind turbines and their magnets; the next generation of photovoltaic cells and inverters; cars with highly efficient combustion engines; batteries (especially 4th generation) for mobility and stationary storage; decarbonized hydrogen; electricity storage systems using hydrogen and batteries; smart grids and demand response solutions; recycling technologies; digital technologies and technologies for protection against cyber risks.
} 
market access rules, despite China's membership of the World Trade Organization (WTO) since 2001.

China has mastery of certain value chains which could give it economic supremacy not only in its large domestic market but also abroad: critical metals and rare earths, their refining, the special alloys of certain metals, innovation, the manufacture and assembly of technologies ( $90 \%$ of solar panels, more than $50 \%$ of onshore wind turbines), third-generation nuclear reactors (China's first project is under construction), batteries, personal and public transport vehicles using electricity or hydrogen (Voïta 2018; IEA 2018)), equipment for managing smart grids or for telecommunications networks $(5 \mathrm{G})$, and soon technologies related to artificial intelligence.

Lastly, China's state companies have unparalleled investment capacities and are making major acquisitions abroad, especially in Europe. They are looking to invest funds at attractive rates of return, but also to take control of technologies, to understand markets and their functioning better, in order to transform their standards, to sell their technologies and identify new assets to acquire. For example, the Three Gorges Company is operating in more than 40 countries and looking to buy assets in the EU. ${ }^{4}$ So is the State Grid Corporation of China, which has earnings of more than $\$ 300$ billion (in 2017) and is seeking to expand its assets across the globe. The development of the $5 \mathrm{G}$ network will play a role in piloting energy systems, and is witnessing the Chinese giant Huawei challenge Western companies like Nokia and Cisco.

This dimension will be particularly accurate with regard to the battery and electric car industries that are currently expanding. The EU will have to further develop its European Battery Alliance (Mathieu 2019) and lay out a mineral strategy to address the critical metals challenge and China's increasing domination of that segment (extraction and refining), implement social responsibility standards, foster innovation to reduce dependency on critical metals, ensure that the low-carbon technologies are built in the EU territory and create local value and jobs and decisively, push forward the circular economy concepts to foster the recycling of metals and plastics, and define and implement the necessary standards. Instruments such as the measure of the carbon footprint of products, or localization norms, will be important.

\section{b. Focus on the vulnerabilities in critical metals}

Our economies have a growing need for critical metals and rare earths in defense, electronics and communications industries, as well as in low-carbon energy transition technologies (alloys, two-thirds of wind turbines use permanent magnets, LEDs, solar panels, glass, smart grids, and digital technologies and batteries). ${ }^{5}$ These so-called critical or strategic metals have exceptional optical, catalytic, chemical, magnetic, and semiconductor properties, for example, neodymium and samarium, allowing super-powerful magnets to be made. Some 30 metals are considered indispensable and difficult to substitute (European Commission 2017).

\footnotetext{
${ }^{4}$ See: www.ctg.com.cn.

${ }^{5}$ Car batteries require $10-20 \mathrm{~kg}$ of cobalt and up to $60 \mathrm{~kg}$ of lithium and other critical metals and rare earths such as neodymium or dysprosium. Solar panels use indium and silicium.
} 
The geographic distribution of these resources, the issues related to the extraction and refining of these metals, the structure of the mining industry as well as their (un-)availability in markets raise numerous challenges. These include geological, political, environmental, technological, social and economic risks which lead to vulnerabilities in the supply chain and so create risks to the value chains of technologies that use them.

The criticality of these metals and rare earths has been much studied and varies depending on the metals and their routes to specific markets: nobody can predict which battery technologies will emerge in the long term, for example, or how solar panels will be built.

These metals are often by-products of more abundant metals, but are present in minute proportions. ${ }^{6}$ A ton of rock needs to be processed just to provide a few grams of platinum. Quantities produced are often tiny compared to other metals: 15 million tons of copper are mined each year and only 600 tons of gallium; 2 billion of iron are produced compared to 200,000 tons of lithium. The quality of deposits varies while the concentration of critical metals may range from 0.5 to $15 \%$, depending on the mines and metals.

Significant environmental issues exist on top of these geological challenges because refining uses lots of water, electricity, and often chemical products for hydrometallic processing with acid. Chile has very large lithium deposits, but needs to ration its production because of water shortages and also competition from copper in particular. Developing infrastructures to transport water is expensive, and this intensifies the criticality of the metal given strong demand growth.

Economic risks are substantial because there are tensions both in supply and demand, as well as market structures which are often oligopolistic, or even dominated by Chinese companies. Strong price volatility of some of these resources is another source of concern as it complicates investment and recycling: this is so notably for cobalt whose price surged before falling in early 2019.

The supply of these metals is concentrated in a small number of countries many of which are not members of the OECD (accepting Canada, Chile, and Australia). They include China, the Democratic Republic of Congo (DRC), Argentina, Bolivia, Russia, South Africa, Kazakhstan, and Brazil.

Mining investment in recent years has concentrated in Latin America and to a lesser extent in Africa. Supply takes a long time to adapt to demand, because the development of mining projects is long to implement. These projects are risky and their profitability is often problematic because of price volatility, and prices were also low for a long time. This situation encouraged the closure of mining activities in Europe and North America, while reinforcing the concentration of such activities in the hands of Chinese companies. The latter do not integrate pollution costs, and they have access to cheap credit, cheap labor, or integrated business structures in which losses in one segment of the value chain are compensated by profits elsewhere.

\footnotetext{
${ }^{6}$ Cobalt is a by-product of nickel and cooper, gallium is a by-product of aluminum; indium and germanium are by-products of zinc for example.
} 
Supplies are often not available in transparent, open, and liquid markets: a share of world production is often allocated outside the market. Rosatom is an important producer of good quality lithium which is used in the Russian nuclear and/or military sector. Only surpluses are sold on markets. Cobalt is mined in the DRC, which accounts for $60 \%$ of global output, and is largely bought directly by the networks of integrated Chinese companies without it being possible to know exactly the output figures of small artisanal mines for example.

Production companies often operate oligopolies, and China has increased its investments and shareholdings and often dominates the extraction and refining of critical metals and rare earths. Thus, five companies account for $90 \%$ of global lithium production, and apart from Abermal and FMC, three of them are Chinese or have Chinese capital (SQM, Tianqi Lithium, and Jiangxi Ganfeng Lithium). The mining of cobalt worldwide is dominated by a few companies including Glencore or Chinese companies which are extending or developing their operations everywhere: in the DRC, in Madagascar, Greenland, and Bolivia. Refining cobalt and lithium is very polluting, and is concentrated in China because producer countries mainly sell intermediate products. ${ }^{7}$ This spectacular strategy by China to expand mining activities and buy up assets has several aims: meeting its needs for metals which are not available in China; pre-empting markets; dealing with growing environmental problems in China; developing more competitive resources; and limiting declines in its own reserves (Seaman 2019). Lastly, apart from these issues, conditions for accessing resources may change: while Argentina and Australia have a very stable investment framework, the DRC has recently adopted a new mining code which increases royalties from 2 to $10 \%$ and plans further increases as mining nationalism is developing notably along the lines of the Bafokeng in South Africa. These developments are often perfectly legitimate but constitute risks for investors and favor actors who can protect themselves from them.

The demand for critical metals is expanding rapidly and is concentrated in emerging countries or countries which are technologically advanced, especially the EU, the US, Japan, and China. Demand for lithium is set to triple by 2025, to reach 600,000 tons per year, and increase by $20 \%$ for copper, and could rise by $60-100 \%$ for cobalt according to various scenarios, requiring at least an increase in output equal to that of the DRC. More generally, the energy transition is likely to be as hungry for other metals and resources which for the moment are not critical, but which could become so. These include copper, iron, or even sand for cement.

Control over the supply chain of critical metals is a strategic asset in developing low-carbon technology value chains and developing advantages over competitors. The EU greatly depends on imports to cover its growing needs because it practically produces none, even though it has non-negligible reserves. The investment framework there, however, is relatively unfavorable and societal opposition is an obstacle despite rising prices and low-interest rates which should allow production to be relaunched. Finland is exceptional in creating a mining cluster ${ }^{8}$ : projects have

\footnotetext{
${ }^{7}$ The refining giants are Huayou, its subsidiary CDM, Jinchuan and GEM.

${ }^{8}$ See: www.miningfinland.com.
} 
been launched on the Keliber site especially so that 11,000 tons per year should be produced by 2020 , while the country has a significant lithium refining industry which will allow it to become a hub in batteries, just as New Caledonia is for nickel. There are some French and European mining and processing groups, such as Eramet, Solvay, Umicore, Imerys, ThyssenKrupp. But their size and global weight are far behind the Asian, Swiss, Canadian, and American giants. There is significant output potential in Greenland but this has already been partly captured by China. Mining projects are emerging in Portugal, Serbia, Hungary, and Germany, but they only represent about $5 \%$ of global annual investment and do not change the overall situation: European dependency on imports will grow.

In a context of heightened economic and technological rivalry, China has a strategic advantage because it can favor its companies at the expense of European customers and so limit the availability of resources or create distortions in competition or use its grip on the chain of critical metals to obtain economic, trade, and technological advantages over European actors. There are important risks in terms of value chains, employment, as well as foreign economic and industrial dependencies. China has, for example, already temporarily reduced its exports of rare earths to Japan following political tensions (Lepesant 2018). Although strategies based on cartel behavior and pressure have not been pursued openly, vulnerabilities remain.

The concentration of resources in a small number of countries outside the OECD, the oligopolistic nature of markets and the fact that these resources are in the hands of powers which are often rivals (especially China and Russia) generate risks for access to resources, and even of emergence of cartels. Both could raise the total costs of the energy transition and block or threaten the development of national industries. This is especially so as competition is strengthening from military technologies, which are also big consumers of critical metals. Faced with trade tensions from the US, China may enhance its strategy of self-sufficiency and reinforce its pre-emption of resources.

Issues related to water, pollution, and the social conditions of mining are also a challenge to corporate social responsibility for European economic actors. There are up to 100 million informal mineworkers in the world who sometimes work in deplorable safety and environmental conditions, while working conditions often do not comply with the standards of the International Labor Organization. The EU should push for higher ESG standards in its imports of critical metals or related materials.

These challenges, risks, and even threats are not new and have been the subject of political and strategic consideration for several years. The EU has a list of 27 critical metals out of 61 that are taken into account (European Commission 2019a, b, c). The US has a substitution strategy, while NATO has formulated goals for reducing dependency of the military industry on China. Yet given the ever greater hegemony of China and the rising challenges of energy transition, a new strategy and evaluation of risks are required. 


\section{c. The battery cells chain}

The demand for Electric Vehicles (EVs) is set to rise strongly as of 2020, due to the combination of: lower costs for electric batteries; restrictions imposed on vehicles with combustion engines (new European emission standards, and traffic restrictions in cities especially); the development of charging infrastructures, and above all the serious commitment of global and European car producers, partly linked to the "dieselgate" scandal. Sales of EVs jumped between 2017 and 2018 and should account for nearly a third of light vehicles sales by 2030. In a favorable scenario, there could be 220 million electric vehicles on road by 2030 compared to 3 million today (IEA 2018).

Factors determining this path include changes in public support measures; the cost of batteries; vehicle autonomy; the availability of fast-charging infrastructures; the environmental and societal footprint of cars; competition and trade strategies; and antipollution regulations in force.

Systems linked to electric vehicles are expanding rapidly but face the following drawbacks:

- the value chain is largely dominated by Asian actors benefiting from subsidies and economies of scale (China, Japan, and Korea), especially in battery cells production. European carmakers need to control the risk of competition moving upstream in the sector;

- load challenges should not be neglected: the development of networks, the management of peaks, and the charging speed: 1 million vehicles generate only about 2 TWh of extra consumption, yet there may be challenges in terms of power demand surges. The partial electrification of France's vehicle fleet could lead to demand peaks of up to $10 \mathrm{GW}$, whose consequences on the network must be anticipated;

- if the carbon footprint of electric vehicles is really to be lower than for conventional vehicles, then they need to be charged with low-carbon electricity. This is the case in France, but not in Poland, for example, which has strong ambitions for reducing city pollution. European regulation at present does not take into account the electricity mix of vehicles. Likewise, life-cycle assessments show that battery manufacturing conditions require substantive amounts of energy and therefore the location of battery gigafactories should also be decided on the basis of environmental criteria;

- without a significant improvement in the energy density of batteries, the search for greater autonomy will run into technical-economic limits. Indeed, the greater vehicle autonomy is, the heavier batteries are and the more metals they consume (500 kg for a Tesla). The creation of interchangeable batteries could nevertheless facilitate the expansion of electric vehicles used for long distances, and reduce charging times.

A combination of technological options should, therefore, be favored so that the goals of cutting $\mathrm{CO}_{2}$ emissions are best achieved in three types of usage: 
- electric mobility: city buses, city fans, cars, two-wheelers, and off-road vehicles;

- carbon-free hydrogen mobility: professional mobility (trucks, long-distance transport), certain trains, shipping; in the long run, possibly aviation;

- natural gas mobility, based on LNG and NGV, but also renewable gas as much as possible: maritime and river transport, long-distance freight transport, family vehicles (presently 1.3 million in the EU). There will still be other forms of pollution like nitrogen oxides, and innovation needs to take place, for them to be filtered especially;

Given that Asian manufacturers are today best placed to capture the bulk of global battery demand, the recent launch of a "European Battery Alliance" is to be welcomed. It is intended to foster the emergence of a European industrial ecosystem by creating a favorable framework for investment in manufacturing capacity. Initial discussions began in the autumn of 2018 and led to a clear diagnosis: without major contracts with the European car industry, it will not be possible to have Europeanled projects that aim directly at achieving an annual production capacity of around $30 \mathrm{GWh}$ per year each, based on the model of the Tesla-Panasonic Gigafactory in Nevada. European car producers are indeed in global competition and believe their negotiating capacity with Asian cells suppliers is sufficient to obtain, today at least, the best cost/performance levels. However, the balance of power is likely to evolve and it is important to be fully aware of becoming technologically dependent on Asia, knowing that a global capacity shortage cannot be excluded. It is, therefore, important to support all intermediate projects (producing $8-10 \mathrm{GWh}$ per year) by 2025 , in order to enter the industrial race and establish the credibility of European suppliers, and for order books to be expanded in the future as development strategies are pursued.

The European Battery Alliance could foreshadow a revival of a European industrial policy which needs to take into account changes in the international rules of the game and find an equilibrium between a wait-and-see position and dirigisme. The Battery Alliance is open and not prescriptive. It is geared to mobilizing private actors and the search for industrial synergies between European actors. The alliance should also draw on a proactive approach by public authorities. All avenues should be explored to improve cost and non-cost competitiveness of European battery manufacture, including an accompanying differentiation strategy; promoting European supply by introducing standards concerning the environmental footprint of batteries; and introducing criteria for the public procurement of electric buses for example. Investment decisions should also be facilitated by mobilizing public funding instruments (the EIB, R\&D programs, IPCEI status authorizing state aid for transnational industrial projects, etc.), or even the design of skill development plans to favor better matching of market needs. Lastly, this new industrial policy should include an external dimension, especially a frank dialogue with China on barriers preventing access to its gigantic electric vehicle market. Success is not guaranteed, but this European Battery Alliance demonstrates a willingness to act without delay, in consultation with European industrial actors and by activating all the available levers of public policy. 
From this point of view, it is to be hoped that the approach will be renewed for other technologies considered to be strategic for the future of the energy transition.

\section{d. The external dimension}

With the expected acceleration and deepening of the European energy transition efforts and policies, the external context will become critical and dedicated and specific policies will have to be developed in order to protect the European transition process. The risk for the EU is to lose its competitiveness, that its economies and companies are weakened, that imports replace carbon-intensive production in the EU ("carbon leakage") and that external actors steel EU's innovations and technologies. It is also that external actors use information technologies to destabilize social and political processes related to this systemic economic and social transformation. Last but not least, it is that the EU is a global island that is pushing for climate neutrality while the rest of the world is on a business as usual trajectory.

The EU will have to develop power instruments, and to make use of these instruments when needed. It could not stop Trump from leaving the Paris Agreement, but it could keep the agreement alive. It could seal a climate pact with China in April 2019. It could not so far prevent Brazil from destroying its Amazonia forest, but is having influence on India, for example, that could strengthen its climate commitments. Overall, instruments that could be mobilized are

- Trade agreements, which so far have no binding climate obligations as highlighted by the Mercosur agreement and follow-up controversy;

- Carbon border adjustment mechanisms at EU's borders for certain goods;

- Public finance: the EBRD, direct contributions such as to the Green Climate Fund, development aid;

- Public diplomacy in bilateral relations and multilateral institutions (OECD, G20, G7);

- Sanctions such as trade restrictions, or limited access to cooperation mechanisms Priorities for actions or issues that will increasingly be in the focus include

- Raising national climate commitments from leading emerging and OECD economies;

- Stopping direct or indirect investments/financing of coal-fired power generation globally;

- Scaling up sustainable electrification in Africa and revisiting multilateral aid mechanisms and projects;

- Greening suffocating cities in emerging economies;

- Fighting deforestation and reforestation;

- Reducing fossil fuel subsidies;

- Improving energy efficiency efforts, especially in the Eastern and Southern neighborhood;

- Reducing the carbon footprint of maritime transport;

- Reducing fugitive methane emissions such as from the natural gas sector. 


\section{Conclusion}

The year 2019 marks a turning point in the European energy transition process which ultimately culminated with the adoption of the carbon neutrality by 2050 . This will require systemic transformation of the EU economies and societies, of its energy policies which will have to include a strong industrial component and decisively, of its external policies. One does not know if the EU will succeed, but this can be achieved. To succeed, the EU will have to reshape all its domestic policies and priorities toward that fundamental goal, while maintaining social and political cohesion. Launching a European Green Deal and mainstreaming the climate neutrality target in all EU policies will have tremendous repercussions for the rest of the world, possibly generating new tensions, but also fueling new alliances and profound geopolitical and geoeconomic transformations.

At the start of this new political cycle for EU institutions, it is essential that the following dimensions are addressed.

Defining carbon neutrality in including imported emissions, determining responsibilities for setting and enforcing climate targets and raising the 2030 targets, reforming the ETS further, notably post-Brexit.

Increasing the capacity for states, regions, and cities to experiment new ways of supporting investment and innovation in low-carbon technologies, while working for enhanced cooperation in the industrial and regulatory fields. These initiatives would begin on a voluntary basis but could be supported and coordinated by a European Energy Transition Agency.

- Implementing a common electricity strategy between France, Belgium, the Netherlands, and Germany within a context of readjusting national electricity mixes and progressive decarbonization. This analysis of regional production equilibriums should also feed the debates on the most relevant interconnection scheme post-Brexit, and on whether new nuclear power stations should be built in the coming decades.

- Given vulnerabilities in critical metals, the EU needs to act and favor new, responsible mining projects on their land, and link their development aid to the implementation of environmental and social standards in the mining sector, while supporting traceability initiatives. Four areas must be pursued simultaneously on the demand side: re-use, recycling, reduction, and reindustrialization.

- Consolidating Europe's industrial policy for low-carbon technologies, by drawing on the initial lessons of the European Battery Alliance. Drawing on a sound diagnosis of present and future technological dependence, as well as on a close dialogue with academia and business, the EU should mobilize all possible public policy tools available (regulations and standards, funding, education, etc.) in order to improve Europe's cost- and non-cost competitiveness. At the same time, the EU should organize a frank dialogue with its trade partners to guarantee fair access to their domestic markets. 
- Accelerating work on the taxonomy in order to promote the large-scale development of green and responsible finance and to encourage investments compatible with the Paris Agreement within the EU, but also with emerging countries.

- Developing a strategic, coherent, and coordinated external energy and climate strategy that would aim to protect the European energy transition process and develop and accelerate the energy transition not only globally, but also decisively, in the EU Eastern and Southern neighborhood, where emissions are $20 \%$ higher than in the EU and could grow further (Eyl-Mazzega 2020).

The energy and climate dimensions have been increasingly dominating the EU policy agenda. A new, broader definition of energy security is required to frame EU's actions and policies. It would entail

- continuous, unimpeded, and guaranteed energy supplies;

- the competitiveness of energy prices in a context of international economic competition;

- the decarbonization of energy sources and their use;

- the mastery and control of innovation, as well as of economic and technological value chains;

- the smooth operation and reliability of integrated, low-carbon energy systems;

- social and territorial cohesion, which are prerequisites for a sustained low-carbon transition.

\section{References}

European Commission (2019a) United in delivering the Energy Union and Climate Action-Setting the foundations for a successful clean energy transition. Communication 285. https://eur-lex.europa.eu/legal-content/EN/TXT/?qid=1565713062913\&uri=CELEX: 52019DC0285. Accessed 18 June 2019

European Commission (2019b) Towards a more efficient and democratic decision making in EU tax policy. Communication. https://ec.europa.eu. Accessed 15 Jan 2019

European Commission (2018) In-depth analysis in support of the commission communication: A clean planet for all, a European long-term strategic vision for a prosperous, modern, competitive and climate neutral economy, November 2018. https://ec.europa.eu

European Commission (2017) Communication from the European Commission to the European Parliament, the Council, the European Economic and Social Committee and the Committee of the Regions, on the 2017 list of critical raw materials for the EU. https://ec.europa.eu. Accessed 13 Sept 2017

European Commission (2019) Critical raw materials. http://ec.europa.eu

Eyl-Mazzega M-A (2020) The green deal's external dimension. Re-engaging with neighbors to avoid carbon walls, Édito Énergie de l'Ifri, 3 March 2020

IEA (2018) Global EV outlook 2018, May 2018. www.iea.org

Intergovernmental Panel on Climate Change (2018) Global Warming of $1,5{ }^{\circ} \mathrm{C}$. Special report, October 2018. www.ipcc.ch

IRENA (2019) Patents evolution of renewable energy. http://resourceirena.irena.org

Lepesant G (2018) La transition énergétique face au défi des métaux critiques. Une domination de la Chine? Études de l'Ifri, Ifri, January 2018 
Mathieu C (2019) The European battery alliance is moving up a gear, Edito de l'Ifri, May 2019 Matthes FC (2017) Decarbonising Germany's power sector: ending coal with a carbon floor price, Notes de l'Ifri, Ifri, December 2017

Seaman J (2019) Rare earth and China: a review of changing criticality in the new economy, Études de l'Ifri, Ifri, January 2019

Voïta T (2018) Going green: are Chinese cities planting the seeds for sustainable energy systems?, Études de l'Ifri, Ifri, February 2019

Open Access This chapter is licensed under the terms of the Creative Commons Attribution 4.0 International License (http://creativecommons.org/licenses/by/4.0/), which permits use, sharing, adaptation, distribution and reproduction in any medium or format, as long as you give appropriate credit to the original author(s) and the source, provide a link to the Creative Commons license and indicate if changes were made.

The images or other third party material in this chapter are included in the chapter's Creative Commons license, unless indicated otherwise in a credit line to the material. If material is not included in the chapter's Creative Commons license and your intended use is not permitted by statutory regulation or exceeds the permitted use, you will need to obtain permission directly from the copyright holder. 